\title{
PROFILE OF PATIENTS ON SICK LEAVE WITH CARPAL TUNNEL SYNDROME
}

\author{
Judson Welber Verissimo de Azevedo ${ }^{1}$, Alexandre Barbosa de Oliveira ${ }^{1}$, Valdênia das Graças Nascimento ${ }^{1}$, \\ Henver Ribeiro de PaIVA FILHO ${ }^{2}$, Leandro VIeCILI ${ }^{3}$, Murilo ANTONIo Rocha ${ }^{1}$
}

\section{ABSTRACT}

Objective: To report clinical and epidemiological characteristics and risk factors of patients with Carpal Tunnel Syndrome (CTS) on sick leave admitted in a University Hospital. Methods: This is a transversal study conducted with patients admitted sequentially over 18 years of age, without distinction of gender and race in the period between September and November 2014. Patients answered a questionnaire and underwent physical examination carried out by the authors. Results: Twenty-five patients were admitted within three months, all females, the mean age was 50.24 years old (standard deviation 10,39) . Among the professions they performed, general and cleaning services were the most prevalent. Most patients featured obesity, followed by depression and systemic arterial hypertension. Approximately half of them were on sick leave. Sleep disorders were also a frequent complaint. Conclusion: CTS is a frequent cause of sick leave and it is related to obesity, dyslipidemia and depression. Level of Evidence IV, Series of Cases.

Keywords: Carpal tunnel syndrome. Workers. Median nerve.

Citation: Azevedo JWV, Oliveira AB, Nascimento VG, Paiva Fillho HR, Viecili L, Rocha MA. Profile of patients on sick leave with carpal tunnel syndrome. Acta Ortop Bras. [online] 2015;23(5):244-6. Available from URL: http://www.scielo.br/aob.

\section{INTRODUCTION}

Carpal tunnel syndrome (CTS) is the most common peripheral neuropathy of the upper limb and a frequent cause of functional disability. ${ }^{1,2}$ The economic consequences are reflected on employers and companies. This peripheral neuropathy is considered a major cause of labor compensation, decreased productivity and disfunction. ${ }^{3}$ Many cases can be prevented by identifying unhealthy workplaces, guidance in the management of performed tasks, proper use of equipment and providing places to reduce physical stress. ${ }^{4}$ Studies have shown an association between CTS and individuals who exert repetitive efforts, non-neutral postures and vibrating activities with their hands. ${ }^{5}$ Individual risk factors for this compression syndrome include age, gender, obesity, pregnancy and other medical conditions such as diabetes and thyroid diseases. ${ }^{6}$

Clinical symptoms of CTS include predominantly nighttime paresthesia, spontaneous pain characterized by proximal irradiation, disappearance of symptoms after vigorous hand movements (shaking sign), neurological deficit and positivity on provocative tests. These include the Tinel sign, triggered by digital percussion to the level of carpal tunnel and flexor retinaculum (the patient reports pain like a shock along the nerve path to the tip of affected fingers). In the Phalen test, there will be paresthesia in the region innervated by the median nerve after wrist flexion for 30-120 seconds. However, none of these clinical signs alone is enough for a clinical diagnosis of CTS. ${ }^{7}$ CTS is more frequent in women (3-10:1), and bilateral involvement is not uncommon. ${ }^{8}$ The risk of acquiring this peripheral neuropathy increases after menopause; moreover, women are more often employed in occupations where there is greater risk of acquiring CTS, as well as housekeeping duties that predispose to the same exposure. ${ }^{8}$

Some studies in the literature show that when only subjective complaints are considered, the prevalence of CTS is greater than when in association with clinical and electromyographic criteria. ${ }^{7}$

The authors aimed to demonstrate the clinical and epidemiological characteristics and the risk factors in patients on sick leave receiving outpatient treatment for carpal tunnel syndrome in a university hospital.

\section{PATIENTS AND METHODS}

This is a cross-sectional study performed at the Hand Surgery Clinic of Hospital de Clínicas da Universidade Federal

All the authors declare that there is no potential conflict of interest referring to this article.

\footnotetext{
1. Universidade Federal do Triângulo Mineiro, Orthopedics and Traumatology Discipline, Hand Surgery Group, Uberaba, MG, Brazil.

2. Faculdade de Medicina de São José do Rio Preto, São José do Rio Preto, SP, Brazil.

3. Fundação Centro de Estudos da Santa Casa de Campo Grande, Campo Grande, MS, Brazil.

Work developed at Universidade Federal do Triângulo Mineiro, Orthopedics and Traumatology Discipline, Hand Surgery Group, Uberaba, MG, Brazil.

Correspondence: Valdênia das Graças Nascimento. Disciplina de Ortopedia e Traumatologia, Hospital de Clínicas da Universidade Federal do Triângulo Mineiro. Av. Getúlio Guaritá,
} 330, Bairro Nossa Senhora da Abadia, 38025-440, Uberaba, MG, Brasil. vallfmtm@yahoo.com.br 
do Triângulo Mineiro, Uberaba, MG, Brazil, with the sequential admission of patients above 18 years of age, without distinction of gender and race, between September and November 2014, by signing the Free and Informed Consent form and approved by the Research Ethics Committee ( $N^{\circ} 950$ 368). Inclusion criteria were patients who had at least one sign and/ or symptom of nerve compression of the medial nerve at the carpal tunnel level. Patients who underwent previous neurolysis of the median nerve at the carpal tunnel level and those with known radiculopathy were excluded from the study.

The patients included answered a questionnaire with signs and symptoms of median nerve compression at the carpal tunnel level, as well as epidemiological data as laterality, dominance, profession, time of disease onset and previous treatments. After this step, they underwent careful physical examination by the authors of this paper (provocative tests of Phalen, Tinel and Durkan, presence of thenar atrophy). The results of electromyography and ultrasound tests were noted if patients had already done these exams, probably ordered by other primary health care physicians, however, these were not asked by the authors for purposes of this work.

\section{RESULTS}

Twenty five patients were admitted, all female, with a mean age $50.24 \pm 10.39$ years old (range $30-79$ years old). Only one patient presented left dominance, while all others were right handed. Eight percent of patients had their left wrist affected, bilateral involvement being prevalent (52.0\%).

Among the occupations performed the following were reported: general services/cleaning (11 patients), household duties (4 patients), production assistant (3), maid (2), hairdresser (2), manicure (1), farmer (1) and cook (1).

Most patients had obesity (44.0\%), followed by depression and hypertension (40.0\% each), dyslipidemia (24.0\%), diabetes and fibromyalgia (16.0\% each), hypothyroidism and smoking (12.0\%). Two or more associated diseases were observed in $60 \%$ of cases. Eighty percent of the patients had depression and made use of antidepressants.

Regarding the provocative tests, $84.0 \%$ were positive for Phalen test, followed by Durkan (68.0\%) and Tinel (60.0\%). Thenar atrophy was observed in three cases and loss of adduction in two. Forty four percent had three or more of the above signals. The onset of symptoms up to 12 months was prevalent in $80.0 \%$ of cases, and only two patients reported symptoms for less than six months.

Approximately half of the patients (48.0\%) were on sick leave from work for 3.6 years on average (range 1-120 months). Of these, most used to work as general services/cleaning (41.67\%), followed by production assistant (16.67\%). A fraction of $58.3 \%$ of patients with CTS on sick leave from work had three or more comorbidities, the most frequent being systemic arterial hypertension (58.33\%), obesity and depression (41.60\% each) and dyslipidemia (25.0\%).

Paresthesia was the most prevalent symptom, being present in all cases followed by nocturnal pain (92.0\%), decreased strength (92.0\%), and daytime pain (87.0\%). Proximal irradiation of pain to the entire upper limb was reported by $68.0 \%$ of respondents. More than half of patients (60.0\%) reported sleeping disorders secondary to the symptoms. The majority of patients had three or more symptoms of median nerve compression at the carpal tunnel level (96.0\%) and of those on sick leave from work only $33.33 \%$ showed three or more symptoms or signs of this compression syndrome.

The use of night splint was reported in $60.0 \%$ of cases, physical therapy and/or occupational therapy in $48.0 \%$. A fifth of patients have had no treatment at all by the time of evaluation.

\section{DISCUSSON}

Carpal tunnel syndrome is the most common peripheral neuropathy ${ }^{9}$ and its diagnosis is based on a combination of clinical signs and symptoms and electromyographic findings. ${ }^{10}$ It is estimated that 1:1000 people are diagnosed annually with CTS according to an English study. ${ }^{11}$

Our study proved the prevalence of carpal tunnel syndrome in middle-aged women and bilateral involvement. Most exerted manual activities related to cleaning and series production. Electromyography and ultrasound examinations were not considered in this work, since it is a cross-sectional study, where most patients were seen as initial consultation and then directed for expert evaluation by other professionals. Therefore, the diagnosis was based on clinical criteria.

Obesity and depression are still reported as risk factors present in various pathologies such as carpal tunnel syndrome overcoming endocrine diseases (diabetes and hypothyroidism), known worldwide as risk factors for the emergence of this peripheral neuropathy. However, studies show that $28 \%$ of diabetics have asymptomatic mononeuropathy of the median nerve. ${ }^{12}$ The presence of two or more co-morbidities in patients with the CTS has been a constant in this study.

Phalen's test was the most sensitive test for evaluating these patients, followed by Durkan's test and Tinel test. Thenar atrophy and loss of adduction have not been prevalent in these cases.

Long term symptoms were found in the vast majority of subjects, with times higher than 12 months of onset of symptoms. Despite paresthesia and night pain are common complaints for most patients, sleeping disorders were frequently reported in almost two thirds of patients with CTS, a value similar of Patel's et $\mathrm{al},{ }^{13}$ who observed $80 \%$ of significant changes of sleeping patterns in patients with this compression syndrome.

CTS is a disease that often affects active working people, causing functional disability and, thus, work compensation. ${ }^{14}$ Most patients under treatment were on sick leave for over three years. Risk factors such as obesity, depression and dyslipidemia overcame traditional endocrine diseases such as diabetes and hypothyroidism, a fact that supports the world scenario with the rise in obesity, dyslipidemia and depression. Activities that require repetitive movements as general services and production assistant are more likely to lead to the development of carpal tunnel syndrome.

Interestingly, only one third of patients with regular labor compensation had three or more signs and symptoms of CTS, meaning that the majority of sick leaves had mildly symptoms or had negative results on clinical examination for CTS. One of the most probable causes of labor compensation constitutes the difficulty that clinicians, medical experts and other specialists who are not Hand Surgery specialists in the clinical management of these patients, considering the prolonged time 
of recovery, socioeconomic difficulties to enable the recommended treatment (orthotics and hand therapy) and lack of rehabilitation programs to the activities previously carried out by the employees themselves.

\section{CONCLUSION}

Carpal tunnel syndrome is a common cause of absence from work in mildly symptomatic patients and is highly related to obesity, dyslipidemia, depression and sleeping disorders.

\section{REFERENCES}

1. Atroshi I, Gummesson C, Johnsson R, Ornstein E, Ranstam J, Rosén I. Prevalence of carpal tunnel syndrome in a general population. JAMA. 1999;282(2):153-8

2. Roquelaure $Y, \mathrm{Ha}$ C, Nicolas G, Pélier-Cady MC, Mariot C, Descatha A, Leclerc A, et al. Attributable risk of carpal tunnel syndrome according to industry and occupation in a general population. Arthritis Rheum. 2008;59(9):1341-8.

3. Stapleton MJ. Occupation and carpal tunnel syndrome. ANZ J Surg 2006;76(6):494-6.

4. Burt S, Crombie K, Jin Y, Wurzelbacher S, Ramsey J, Deddens J. Workplace and individual risk factors for carpal tunnel syndrome. Occup Environ Med. 2011;68(12):928-33.

5. Burt S. Hand/wrist musculoskeletal disorders: evidence for work relatedness. In: Bernard B, ed. Musculoskeletal Disorders and Workplace Factors: A Critical Review of Epidemiologic Evidence for Work-Related Musculoskeletal Disorders of the Neck, Upper Extremity, and Low Back. Cincinnati OH: US Department of Health and Human Services, NIOSH, 1997:5a1-c31. (Publication 97-141).

6. Atcheson SG, Ward JR, Lowe W. Concurrent medical disease in work-related carpal tunnel syndrome. Arch Intern Med. 1998;158(14):1506-12
7. Giersiepen K, Spallek M. Carpal tunnel syndrome as an occupational disease. Dtsch Arztebl Int. 2011;108(14):238-42.

8. de Krom MC, Knipschild PG, Kester AD, Thijs CT, Boekkooi PF, Spaans F. Carpal tunnel syndrome: prevalence in the general population. J Clin Epidemiol. 1992;45(4):373-6.

9. Bland JD. Carpal tunnel syndrome. BMJ. 2007;335(7615):343-6.

10. Rempel D, Evanoff B, Amadio PC, de Krom M, Franklin G, Franzblau A, et al. Consensus criteria for the classification of carpal tunnel syndrome in epidemiologic studies. Am J Public Health. 1998;88(10):1447-51.

11. McCormick A, Fleming D, Charlton J. Morbidity statistics from general practice. 4th national study 1991-2. Series MB5 No 3. London: HMSO; 1992.

12. Stamboulis E, Voumvourakis K, Andrikopoulou A, Koutsis G, Tentolouris N, Kodounis $A$, et al. Association between asymptomatic median mononeuropathy and diabetic polyneuropathy severity in patients with diabetes mellitus. J Neurol Sci. 2009;278(1-2):41-3

13. Patel A, Culbertson MD, Patel A, Hashem J, Jacob J, Edelstein D, et al. The negative effect of carpal tunnel syndrome on sleep quality. Sleep Disord. 2014;2014:962746.

14. Palmer KT. Carpal tunnel syndrome: the role of occupational factors. Best Pract Res Clin Rheumatol. 2011;25(1):15-29. 